\title{
Radiation treatment of cancer of the eyelids
}

\author{
M. LEDERMAN \\ From the Royal Marsden Hospital and Moorfields Eye Hospital, London
}

Eyelid cancers are not uncommon tumours and are usually basal cell or more rarely squamous cell in character. Their importance lies in their special situation since unlike cancer arising elsewhere in the skin they can by their natural progression or as a consequence of the effects of treatment cause impairment or even loss of vision. Although these tumours are 'malignant', death of the patient rarely results from failure of local control, unless the disease is very advanced or was mismanaged at the outset. In the case of squamous cell cancer, death may occasionally result from metastatic spread.

It should be an obvious ethical maxim that no patient should be submitted to a major surgical operation if an established and equally effective alternative non-surgical procedure is available. In the case of skin cancer generally and the lids in particular radiotherapy provides such an alternative since its curative value has been firmly established during the past 50 years. The reluctance of ophthalmologists to advise the use of radiant energy appears to relate to the calamities that first attended its use by the pioneer ophthalmologists at the beginning of this century. The story of their heritage of ocular disasters has been transmitted from generation to generation ignoring the fact that progress in radiotherapy has been such that under modern conditions most of the complications, particularly the more gruesomely destructive ones, can largely be avoided. In view of this the presentday tendency to submit patients suffering from lid neoplasms indiscriminately to simple excisional or plastic surgical procedures without considering an established alternative would seem unjustifiable.

This report on a series of 896 patients (Table I) seen at the Royal Marsden Hospital during the period $1945-70$ describes some of the features of the natural history of lid cancer and by giving the results, contraindications, and complications of radiation treatment evaluates this method in the treatment of lid cancer. The series is a relatively large one and the high proportion of 'previously untreated' cases reflects the value of the longstanding liaison the Royal Marsden Hospital has

Address for reprints: M. Lederman, FRCR, Chairman, Division of Radiotherapy and Oncology, Royal Marsden Hospital, Fulham Road, London $\mathrm{SW}_{3}$ 6JJ had with the main eye hospitals in London and also it is to be hoped demonstrates the confidence that many ophthalmologists have in radiotherapy.

Histological verification was obtained in 562 of the 630 cases of basal cell carcinoma. In most of the 68 cases lacking verification, a biopsy was taken but this proved inadequate or was otherwise unsatisfactory and by the time the report became available the treatment had reached a stage where repetition of the biopsy would have provided no useful information.

There is some doubt concerning the diagnosis of one case of squamous carcinoma. The inclusion of the ro per cent of patients who lack histological confirmation can be excused because the clinical diagnosis of a basal cell carcinoma of the skin is usually easy and the response to radiation typical. In any event this proportion of the cases is small enough not to vitiate the conclusions drawn from this study.

Of the 689 previously untreated patients a number had had an excision biopsy before radiotherapy: some 80 patients had had an attempted primary excision but were promptly referred for postoperative radiotherapy because the pathological report showed that removal had been incomplete.

The recurrent cases comprise those patients whose symptoms recurred after receiving some form of surgery or radiotherapy at other hospitals (104 excisions; three excision and radiotherapy; five radiotherapy; five excision and plastic repair). These patients were referred to the Royal Marsden Hospital for treatment after frank recurrence had taken place. The patients seen and not treated include those who were referred for an opinion, some who were advised to have surgery, and a few patients who refused treatment.

Table I Squamous and basal cell carcinomas of eyelids and canthi, $1945-70$

\begin{tabular}{|c|c|}
\hline Patients & No. \\
\hline Previously untreated cases & 689 \\
\hline Recurrent cases & I I 7 \\
\hline Cases seen and not treated & 90 \\
\hline Total & 896 \\
\hline
\end{tabular}


Tables II $a, b$ show the regional distribution of the tumours in relation to their sex incidence. The well-known preponderance of tumours on the lower lid and inner canthus is well shown. The basal cell carcinomas are approximately to times more common than the squamous carcinomas but the latter form a higher proportion of the tumours of the upper lid and outer canthus. The sex ratios are male/female: $1 \cdot 23$ for the basal cell carcinomas and 2.93 for the squamous carcinomas.

Table III shows the age incidence illustrating the fact that most of the patients are elderly.

Table IV shows there is little of significance in relation to site or sex: but in the basal cell carcinomas there would appear to be a right-sided male predominance while in females the inner canthus lesion was more common on the left side.

\section{Topographical distribution}

It is customary to divide the site of origin of lid tumours into upper and lower lid; inner and outer

Table IIa Basal cell carcinoma. Distribution according to site and sex (630 patients)

\begin{tabular}{|c|c|c|c|c|c|c|}
\hline \multirow[b]{2}{*}{ Site } & \multicolumn{2}{|c|}{ Male } & \multicolumn{2}{|c|}{ Female } & \multicolumn{2}{|c|}{ Total } \\
\hline & No. & Percentage & No. & Percentage & No. & Percentage \\
\hline $\begin{array}{l}\text { Upper lid } \\
\text { Lower lid }\end{array}$ & 45 & $\begin{array}{l}12.9 \\
61.8\end{array}$ & 29 & $\begin{array}{l}10.3 \\
60.6\end{array}$ & $\begin{array}{r}74 \\
286\end{array}$ & II $\cdot 7$ \\
\hline $\begin{array}{l}\text { Lower lid } \\
\text { Inner canthus }\end{array}$ & $\begin{array}{r}215 \\
76\end{array}$ & $\begin{array}{r}01 \cdot 8 \\
2.8\end{array}$ & $\begin{array}{r}171 \\
77\end{array}$ & 60.6 & 380 & $6 I \cdot 3$ \\
\hline $\begin{array}{l}\text { Inner canthus } \\
\text { Outer canthus }\end{array}$ & $\begin{array}{l}70 \\
12\end{array}$ & $\begin{array}{r}21 \cdot 8 \\
3 \cdot 5\end{array}$ & $\begin{array}{r}77 \\
5\end{array}$ & $\begin{array}{r}27 \cdot 3 \\
1 \cdot 8\end{array}$ & $\begin{array}{r}153 \\
17\end{array}$ & $\begin{array}{r}24.3 \\
2.7\end{array}$ \\
\hline Total & 348 & 100 & 282 & 100 & 630 & 100 \\
\hline
\end{tabular}

Table IIb Squamous carcinoma. Distribution according to site and sex (59 patients)

\begin{tabular}{|c|c|c|c|c|c|c|}
\hline \multirow[b]{2}{*}{ Site } & \multicolumn{2}{|c|}{ Male } & \multicolumn{2}{|c|}{ Female } & \multicolumn{2}{|c|}{ Total } \\
\hline & No. & Percentage & No. & Percentage & No. & Percentage \\
\hline Upper lid & 16 & $36 \cdot 4$ & 3 & $20 \cdot 0$ & 19 & $32 \cdot 2$ \\
\hline Lower lid & 17 & $38 \cdot 6$ & 8 & $53 \cdot 3$ & 25 & $42 \cdot 3$ \\
\hline Inner canthus & 5 & $11 \cdot 4$ & 4 & $26 \cdot 7$ & 9 & I $5 \cdot 3$ \\
\hline Outer canthus & 6 & $13 \cdot 6$ & 一 & 一 & 6 & 10.2 \\
\hline Total & 44 & 100 & 15 & 100 & 59 & 100 \\
\hline
\end{tabular}

Table III Carcinomas of eyelids and canthi. Age incidence of new cases

\begin{tabular}{|c|c|c|c|c|}
\hline & \multicolumn{2}{|c|}{ Basal cell } & \multicolumn{2}{|c|}{ Squamous cell } \\
\hline & Male & Female & Male & Female \\
\hline $\begin{array}{l}\text { Average ages } \\
\text { (years) }\end{array}$ & $60 \cdot 8$ & $64 \cdot 2$ & $61 \cdot 0$ & $65 \cdot 5$ \\
\hline Youngest & 20 & 18 & 34 & 49 \\
\hline Oldest & 87 & 94 & 87 & 88 \\
\hline
\end{tabular}

Table IV Laterality by site and sex

\begin{tabular}{|c|c|c|c|c|}
\hline \multirow{2}{*}{$\begin{array}{l}\text { Basal cell } \\
\text { carcinoma }\end{array}$} & \multicolumn{2}{|c|}{ Males } & \multicolumn{2}{|c|}{ Females } \\
\hline & Left & Right & Left & Right \\
\hline Upper lid & 16 & 29 & I I & 18 \\
\hline Lower lid & 98 & 117 & 85 & 85 \\
\hline Inner canthus & 36 & 40 & 48 & 29 \\
\hline Outer canthus & 6 & 6 & 3 & 2 \\
\hline Total & 156 & 192 & 147 & I 34 \\
\hline \multicolumn{5}{|c|}{ Squamous cell carcinoma } \\
\hline Upper lid & 8 & 8 & $\mathbf{I}$ & 2 \\
\hline Lower lid & 9 & 8 & 4 & 4 \\
\hline Inner canthus & 4 & $\mathbf{I}$ & 4 & - \\
\hline Outer canthus & $\mathbf{I}$ & 5 & - & 一 \\
\hline Total & 22 & 22 & 9 & 6 \\
\hline
\end{tabular}

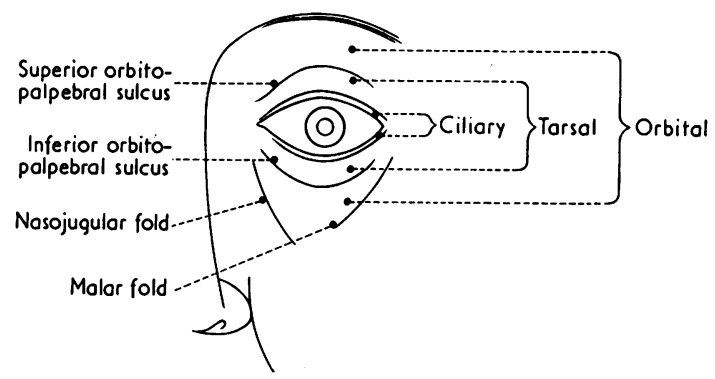

FIG. I Anatomical subdivisions of the lid

canthus. However, in most early lid tumours it is possible to be more precise with regard to the particular part of the lid from which the tumour arises. In Fig. I the palpebral structures have been divided into their anatomical components-that is, inner and outer canthus and ciliary, tarsal, and palpebral parts for each lid. It has proved possible to allocate some 80 per cent of tumours of the upper lid and 90 per cent of those of the lower lid to one of these three sites of origin. For the more extensive tumours where the lid is involved for its whole extent the term 'whole' has been used and for the very advanced cases with involvement of the globe or orbit the term 'unclassifiable' has been employed.

Table $\mathrm{V}$ shows the topographical distribution according to the scheme outlined above. It can be seen that in both upper and lower lids the tarsal portion is most commonly affected but the ciliary portion is affected three times as frequently in the lower lid than the upper; whereas in the upper lid the orbital portion is affected nearly three times as commonly as in the lower lid.

The incidence of advanced tumours is also very 

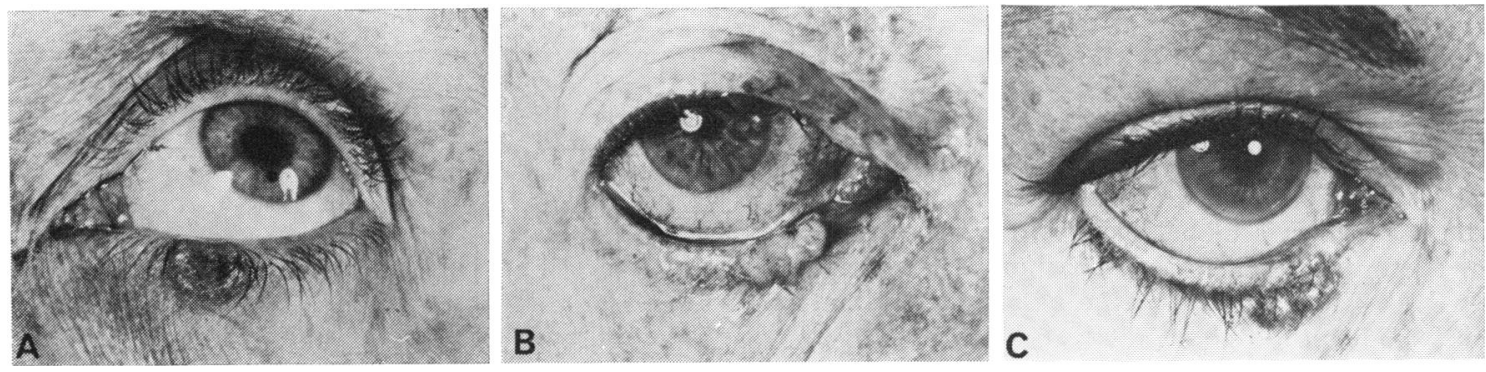

FIG. 2 Lower lid tumours. (a) ciliary;

(b) ciliary; (c) tarsal
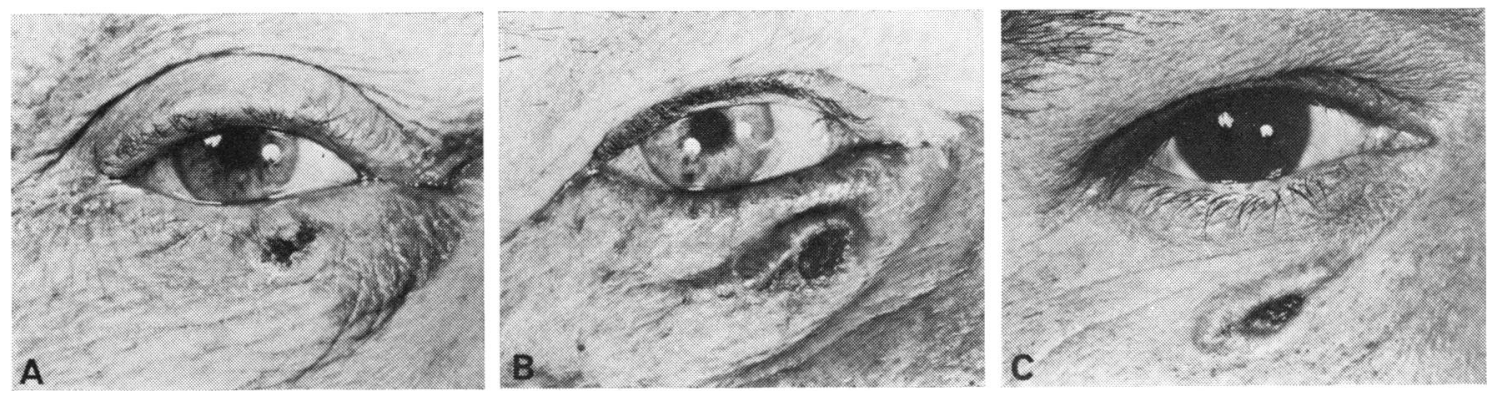

FIG. 3 Lower lid tumours. (a) tarsal; (b) tarsal; (c) orbital

Table V Topographical subdivision (689 patients)

\begin{tabular}{|c|c|c|c|c|c|c|}
\hline \multirow{2}{*}{$\frac{\text { Site }}{\text { Upper lid }}$} & \multicolumn{2}{|c|}{ Basal cell } & \multicolumn{2}{|c|}{ Squamous cell } & \multicolumn{2}{|c|}{ Total } \\
\hline & $\begin{array}{r}\text { No. } \\
12\end{array}$ & $\begin{array}{l}\text { Percentage } \\
\text { I } 6\end{array}$ & $\underset{\mathbf{I}}{N o .}$ & $\begin{array}{l}\text { Percentage } \\
5\end{array}$ & $\begin{array}{r}\text { No. } \\
\text { I3 }_{3}\end{array}$ & $\begin{array}{l}\text { Percentage } \\
\text { I4 }\end{array}$ \\
\hline Tarsal & 32 & 43 & 5 & 25 & 37 & 40 \\
\hline Orbital & 21 & 28 & 5 & 25 & 26 & 27 \\
\hline Whole & 6 & 8 & 7 & 36 & 13 & 14 \\
\hline Unclassifiable & 3 & 4 & $\mathbf{I}$ & 5 & 4 & 5 \\
\hline Total & 74 & 80 & 19 & 20 & 93 & 100 \\
\hline \multicolumn{7}{|l|}{ Lower lid } \\
\hline Ciliary & 116 & 30 & 8 & 32 & 124 & 30 \\
\hline Tarsal & 189 & 48 & 15 & 60 & 204 & 50 \\
\hline Orbital & 43 & I I & I & 4 & 44 & 10 \\
\hline Whole & 30 & 7 & $\mathbf{I}$ & 4 & 31 & 7 \\
\hline Unclassifiable & 8 & 2 & - & - & 8 & 2 \\
\hline Total & 386 & 94 & 25 & 6 & 411 & 100 \\
\hline Inner canthus & 53 & 95 & 9 & 5 & 162 & 100 \\
\hline Outer canthus & 17 & 73 & 6 & 27 & 23 & 100 \\
\hline Total & 630 & & 59 & & 689 & \\
\hline
\end{tabular}

different in each lid. Nineteen per cent of the upper lid tumours are advanced (whole and unclassifiable) as opposed to 9 per cent in the lower lid. The reasons for this are possibly:

I. The greater incidence of ciliary lesions on the lower lid which are more likely to produce irritative symptoms.

2. The presence of epiphora if the lower punctum is involved.

3. On gazing directly at the eye the whole of the lower lid is open to inspection by the patient whereas to see the whole of the upper lid the affected eye has to be closed or the lid pulled down and inspection is therefore much more difficult.

Figs 2 to 6 illustrate the different topographical sites. The differentiation between ciliary and tarsal lesions is often difficult but in Fig. 2 it can be seen that in early lesions the lashes provide a reasonable baseline for identification. In the ciliary site the tumour is above the lashes or the lashes bisect it equally, whereas in the tarsal lesion the lash margin may be free or if it is involved the bulk of the tumour is below this line. The separation between tarsal and orbital lesions rarely presents problems although when both parts of the lid are affected the butk of the tumour is usually on one or other side of the orbitopalpebral sulcus. Loss of lashes in relation to the tumour may occur with both tarsal and ciliary lesions, but usually the remaining lashes help in identifying the level of origin of a given tumour.

Figs 7a, $b$ (Mustardé and Jones, 1970) show schematically the direction and site of insertion of the main fasciculi of the orbicularis oculi muscle.

It is not too difficult to imagine the similarity between the distribution of these sphincteric fasciculi and the sites of origin of the overlying skin tumours. Equally the frequency with which the inner canthus and lower lid are involved seems to be reflected in the manner and site of insertion of the muscle fibres. 
FIG. 4 Upper lid tumours. (a) ciliary; (b) ciliary; (c) tarsal ; (d) orbital
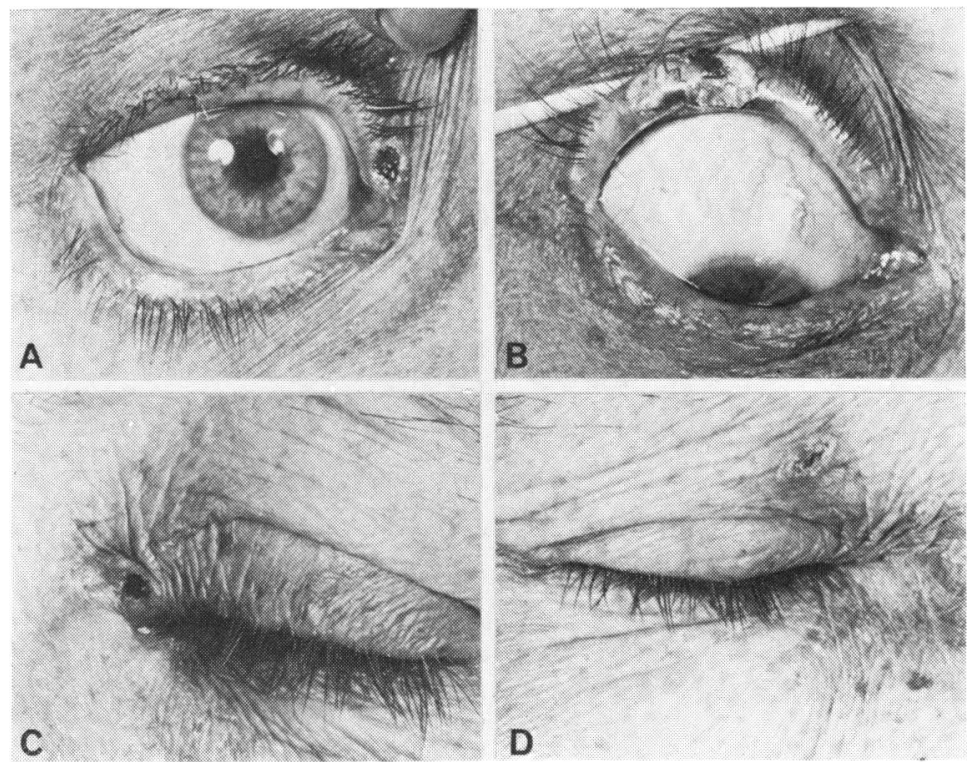

FIG. 5 Inner canthus.

(a) commissure free; (b) invasion of commissure; (c) invasion of upper lid; (d) invasion of lower lid

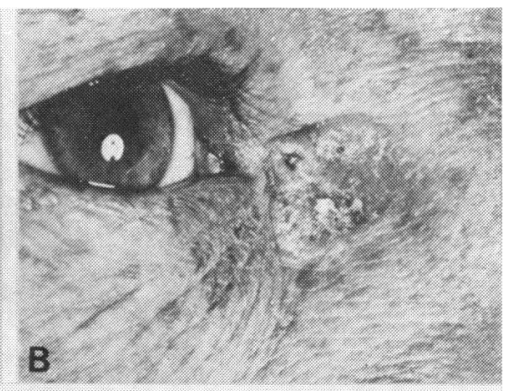

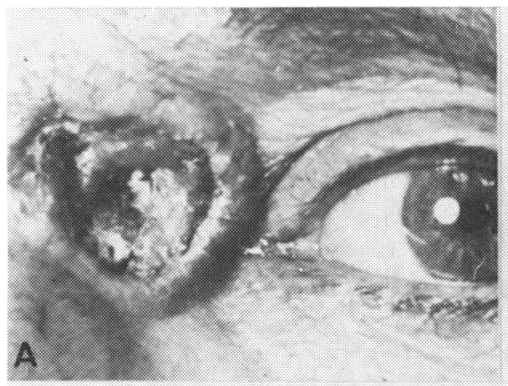
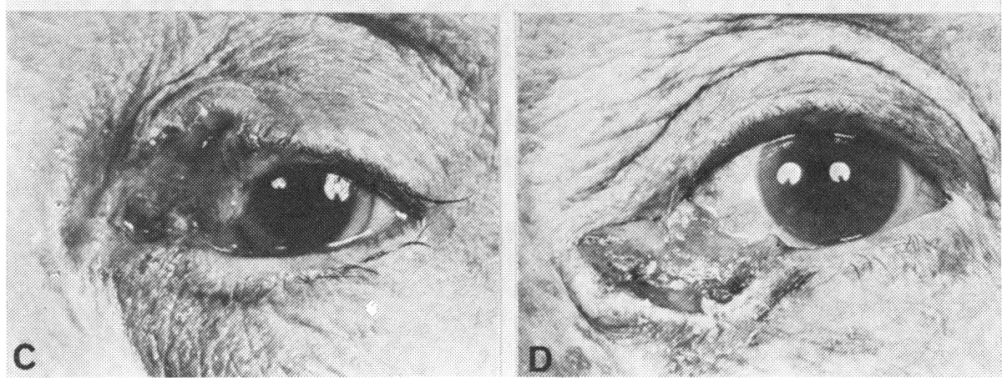

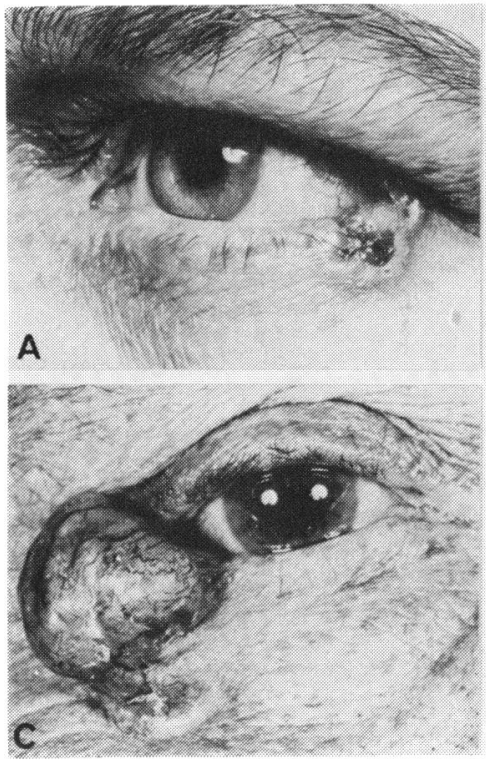
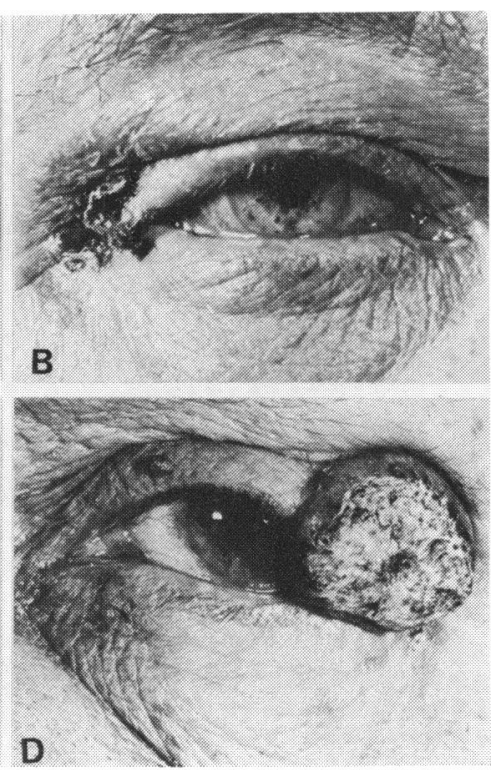

FIG. 6 Outer canthus. (a) invasion of lower lid; (b) invasion of upper lid; (c) invasion of canthus and lower lid extending down to the orbital part of the lid; (d) invasion of canthus with extension into the tarsal and orbital part of the upper lid given sphincteric mechanism. In this series there were 19 patients with basal cell carcinoma who presented with multiple lid tumours. Thirty-three patients had multiple tumours involving lids and other parts of the skin, and 24 subsequently developed further skin tumours not necessarily of the lid.

Among the squamous cancers three patients had multiple lid tumours, four had multiple skin cancers, and three later developed other skin tumours.

\section{TNM classification (UICC, I974)}

There is a special committee of the International Union against Cancer (UICC) (designated the Committee on Clinical Stage Classification and Applied Statistics) one of whose functions it is to

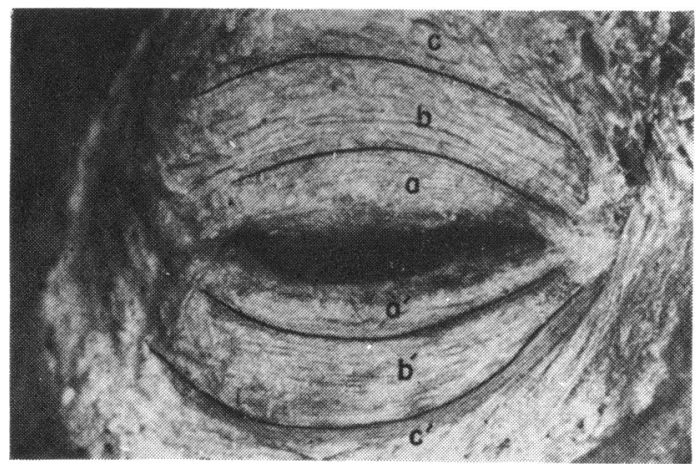

FIG. 7 (a) Orbicularis oculi muscle. (a-a') pretarsal part; (b-b') preseptal part; (c-c') orbital part

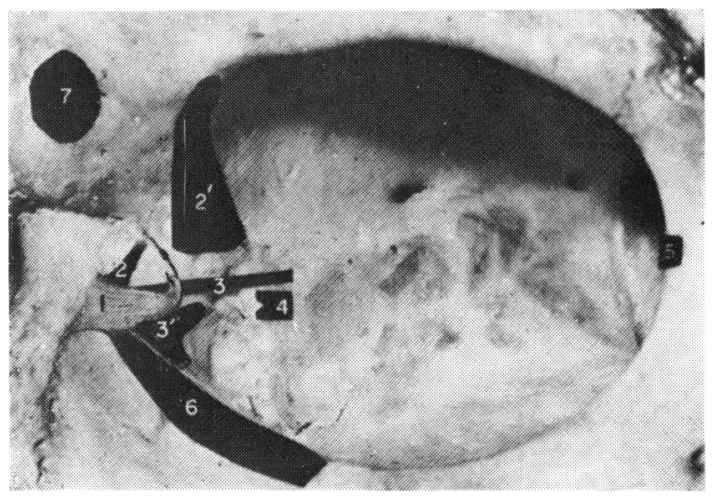

FIG. 7 (b) Insertions of the orbicularis oculi muscle.

(I) medial canthal tendon made up of superficial heads of pretarsal muscles; (2-2') Superciliaris and upper orbital muscle; (3-3') preseptal muscles; (4) deep heads of pretarsals; (5) lateral canthal tendon of pretarsal muscles; (6) lower orbital muscle (from Ophthalmic Plastic Surgery Up-to-Date, Lester T. Fones)

extend the general technique of classification to cancer at all sites.

Tumour classification is important and where adopted internationally has the following advantages:

I. It provides a means of communication that transcends language barriers.

2. It assists in the evaluation and comparison of treatment results.

3. It helps in the selection of treatment methods. 4. It aids prognosis.

Many cancer sites have been the subject of study 
by this Committee and international agreement has been reached on some.

A classification for skin cancer has been recommended by the Committee and is meant to be applicable to tumours of the eyelids. In practice its implementation is difficult since it is dependent on tumour measurements and the dimensions it selects (2 and $5 \mathrm{~cm}$ ) as a basis for classification are not readily relevant to the average lid tumour, Table VI.

In this series of cases the precise dimensions of the tumour were not routinely recorded since the site and extent of the lid involvement was expressed in topographical terms so as to indicate the manner and direction of tumour spread. However, some idea of the size of the tumour can be obtained from the maximum dimension of the field size used in treatment (this usually included a minimum margin of $5 \mathrm{~mm}$ of apparently normal skin surrounding the lesion) (Halman and Britten, 1960). Tables VII $a, b$ show the distribution of the basal cell and squamous cell carcinomata according to the field sizes used in treatment. The tumour of $3 \mathrm{~cm}$ or less would presumably correspond to the TI group, the 3 to 3.9

Table VI TNM classification applicable to tumours of the skin of the eyelid (UICC, 1974)

T-Primary tumour

TIS Pre-invasive carcinoma (carcinoma in situ).

To No primary tumour present.

TI Tumour $2 \mathrm{~cm}$ or less in its largest dimension, strictly superficial or exophytic.

T2 Tumour more than $2 \mathrm{~cm}$ but not more than $5 \mathrm{~cm}$ in its largest dimension or with minimal infiltration of the dermis, irrespective of size.

$\mathrm{T}_{3}$ Tumour more than $5 \mathrm{~cm}$ in its largest dimension or with deep infiltration of the dermis, irrespective of size.

$\mathrm{T}_{4}$ Tumour involving other structures such as cartilage, muscle, or bone.

\section{$\mathrm{N}$-Regional lymph nodes}

The clinician may record whether palpable nodes are considered to contain growth or not.

No No palpable nodes.

Ni Movable homolateral nodes.

$\mathrm{Ni} a$ Nodes not considered to contain growth. $\mathrm{NI} b$ Nodes considered to contain growth.

N2 Movable contralateral or bilateral nodes. N2a Nodes not considered to contain growth. $\mathrm{N}_{2} b$ Nodes considered to contain growth.

$\mathrm{N}_{3}$ Fixed nodes.

M-Distant metastases

Mo No evidence of distant matastases.

MI Distant metastases present including lymph nodes beyond the region in which the primary tumour is situated or satellite nodules more than $5 \mathrm{~cm}$ from the border of the primary tumour.
Table VIIa Basal cell carcinoma: new cases

\begin{tabular}{|c|c|c|c|c|}
\hline \multirow[b]{2}{*}{ Site } & \multicolumn{4}{|c|}{ Field size } \\
\hline & $\begin{array}{l}<3 \\
\mathrm{~cm}\end{array}$ & $\begin{array}{l}3-3 \cdot 9 \\
\mathrm{~cm}\end{array}$ & $\begin{array}{l}\geqslant 4 \\
c m\end{array}$ & $\begin{array}{l}\text { Total size } \\
\text { unknown }\end{array}$ \\
\hline Upper lid (no.) & 28 & 32 & I3 & 73 \\
\hline Percentage & $38 \cdot 4$ & $43 \cdot 8$ & $17 \cdot 8$ & $100 \cdot 0$ \\
\hline Lower lid (no.) & 139 & 166 & 79 & 384 \\
\hline Percentage & $36 \cdot 2$ & $43 \cdot 2$ & $20 \cdot 6$ & $100 \cdot 0$ \\
\hline Inner canthus (no.) & 96 & 40 & 16 & 152 \\
\hline Percentage & $63 \cdot 2$ & $26 \cdot 3$ & 10.5 & $100 \cdot 0$ \\
\hline Outer canthus (no.) & 5 & 8 & 4 & 17 \\
\hline Percentage & $29 \cdot 4$ & $47^{\cdot I}$ & 23.5 & $100 \cdot 0$ \\
\hline Total (no.) & 268 & 246 & I 12 & 626 \\
\hline Percentage & $42 \cdot 8$ & $39 \cdot 2$ & I $8 \cdot 0$ & $100 \cdot 0$ \\
\hline
\end{tabular}

Note: 4 cases with unrecorded field size excluded

Table VIIb Squamous cell carcinoma: new cases

\begin{tabular}{|c|c|c|c|c|}
\hline \multirow[b]{2}{*}{ Site } & \multicolumn{4}{|c|}{ Field size } \\
\hline & $\begin{array}{l}<3 \\
c m\end{array}$ & $\begin{array}{l}3-3.9 \\
\mathrm{~cm}\end{array}$ & $\begin{array}{l}\geqslant 4 \\
\mathrm{~cm}\end{array}$ & $\begin{array}{l}\text { Total size } \\
\text { unknown }\end{array}$ \\
\hline Upper lid & 7 & 2 & 10 & 19 \\
\hline Lower lid & I0 & 15 & - & 25 \\
\hline Inner canthus & 3 & 4 & 2 & 9 \\
\hline Outer canthus & - & 2 & 3 & 5 \\
\hline Total (no.) & 20 & 23 & I 5 & 58 \\
\hline Percentage & $34 \cdot 5$ & $39 \cdot 6$ & $25^{\circ} 9$ & $100 \cdot 0$ \\
\hline
\end{tabular}

Not: I case with unrecorded field size excluded

group to $\mathrm{T}_{2}$, and greater than $4 \mathrm{~cm}$ to $\mathrm{T}_{3}$ and $\mathrm{T}_{4}$. There were only three $\mathrm{N}_{\mathrm{I}}$ cases in the squamous group.

\section{Results of treatment}

In assessing the results obtained in the treatment of basal cell carcinomas the five-year survival rate customarily adopted as a measure of success for cancer generally is applicable with certain reservations since in the head and neck basal cell carcinomata do not metastasize and even if untreated the patient may survive many years. A simpler and more acceptable parameter for assessing the success or failure of treatment is to base this on the recurrence-free rate. Tables VIII $a, b$ show this for basal cell carcinoma of the different sites. Only two patients actually died of uncontrolled disease, although in three other cases the cause of death was unknown.

A recurrence-free rate of at least 90 per cent or 
Table VIIIa Basal cell carcinoma. Recurrence-free rates (all sites and all patients)

\begin{tabular}{|c|c|c|c|}
\hline \multicolumn{2}{|c|}{ Lower lid (all sites) } & \multicolumn{2}{|c|}{ Inner canthus } \\
\hline \multicolumn{2}{|c|}{ Initially at risk $=3^{86}$} & \multicolumn{2}{|c|}{ Initially at risk $=I_{53}$} \\
\hline \multicolumn{2}{|c|}{ Recurrence-free } & \multicolumn{2}{|c|}{ Recurrence-free } \\
\hline Years & Percentage & Years & Percentage \\
\hline $\mathbf{I}$ & $97 \cdot 3$ & $\mathbf{I}$ & $94 \div 7$ \\
\hline 2 & $95^{\circ} 9$ & 2 & $93 \cdot 2$ \\
\hline 3 & $95 \cdot 3$ & 3 & $91 \cdot 7$ \\
\hline 4 & $95^{\circ} \circ$ & 4 & $90 \cdot 8$ \\
\hline 5 & $94 \div 3$ & & \\
\hline 10 & $93 \cdot 7$ & & \\
\hline$>10$ & None & $>4$ & None \\
\hline
\end{tabular}

Table VIIIb Basal cell carcinoma

All patients : upper lid (all sites)

74 initially at risk

No recurrences in a maximum period of

observation of 15 years

All patients : outer canthus

I 7 initially at risk

I recurrence only-within I year

more establishes the value of radiation treatment since unless the sample is small or case selection, or more commonly, dubious statistical manipulation has taken place, there is no cancer site in the body however early the lesion where a Ioo per cent cure rate is achieved.

In the case of the squamous carcinomas with their potentialities for metastasis a different mode of presentation of results is necessary. To emphasize the greater gravity of these lesions even when affecting the skin, the recurrence-free rate, the crude survival rates, and the incidence of lymph node metastases are given in Tables IX and X. One-third of the patients died within five years but of these only three succumbed to their cancer and in four cases the cause of death was unknown: the remaining deaths were due to intercurrent disease.

\section{Complications}

In the 22 years between the publication of Textbook of Ophthalmology, vol. V (Duke-Elder, 1952) and System of Ophthalmology, vol. XIII (Duke-Elder, 1974) Duke-Elder's views on the relative roles of radiotherapy and surgery in the treatment of eyelid tumours underwent a profound change. In 1952
Duke-Elder stated that excision should be the rule and radiation the exception' whereas in 1974 he considered that 'excision or radiotherapy .... are probably equally effective... when efficiently carried out'.

In common with Haye, Jammet, and Dollfus (r965) Duke-Elder emphasizes that the fear of radiation complications is often the main reason for preferring surgery to radiotherapy. There is little doubt that were it possible to establish that lid tumours could be treated by radiotherapy with an acceptable minimum of complications a formidable case could then be made for its preferential use.

Table XI lists the complications encountered in this series of cases. Three complications are not specially listed:

Telangiectasia with or without depigmentation (I2 per cent)

The radiotherapist's attitude towards telangiectasia should parallel that taken by the surgeon towards postoperative scars. There is no guarantee that any scar whether surgical or radiational will always be cosmetically acceptable although much can be done technically by both the surgeon and the radiotherapist towards achieving a satisfactory non-disfiguring scar.

Table IX Squamous cell carcinoma. Survival rate by site

\begin{tabular}{|c|c|c|c|}
\hline Site & $\begin{array}{l}\text { Patients at } \\
\text { risk } 5 \text { years } \\
\text { and followed- } \\
\text { up }\end{array}$ & $\begin{array}{l}\text { Alive } 5 \\
\text { years }\end{array}$ & $\begin{array}{l}\text { 5-year } \\
\text { survival } \\
\text { (percentage) }\end{array}$ \\
\hline Upper lid & I 8 & 12 & 67 \\
\hline Lower lid & 23 & I 8 & 78 \\
\hline Inner canthus & 6 & 2 & - \\
\hline Outer canthus & 4 & 2 & - \\
\hline Total & $5 \mathrm{I}$ & 34 & 67 \\
\hline
\end{tabular}

Table X Recurrence-free rate for all sites. Lymph node involvements (59 patients)

\begin{tabular}{|c|c|c|c|c|}
\hline \multirow[b]{2}{*}{ Site } & \multirow{2}{*}{$\begin{array}{l}\text { Not } \\
\text { involved }\end{array}$} & \multicolumn{2}{|l|}{ Involved } & \multirow[b]{2}{*}{ Total } \\
\hline & & Initially & Later & \\
\hline Upper lid & I 6 & 2 & $\mathbf{I}$ & 19 \\
\hline Lower lid & 25 & - & - & 25 \\
\hline Inner canthus & 8 & - & $\mathbf{I}$ & 9 \\
\hline Outer canthus & 4 & 2 & - & 6 \\
\hline Total & 53 & 4 & 2 & 59 \\
\hline
\end{tabular}

In nine previously treated cases, two had nodes involved later Recurrence-free percentage: I year $(87.5$ per cent $)$

No recurrences observed beyond I year 
FIG. 8(a) Extensive carcinoma of lower lid before treatment

FIG. 8(b) After treatment showing lid deformity

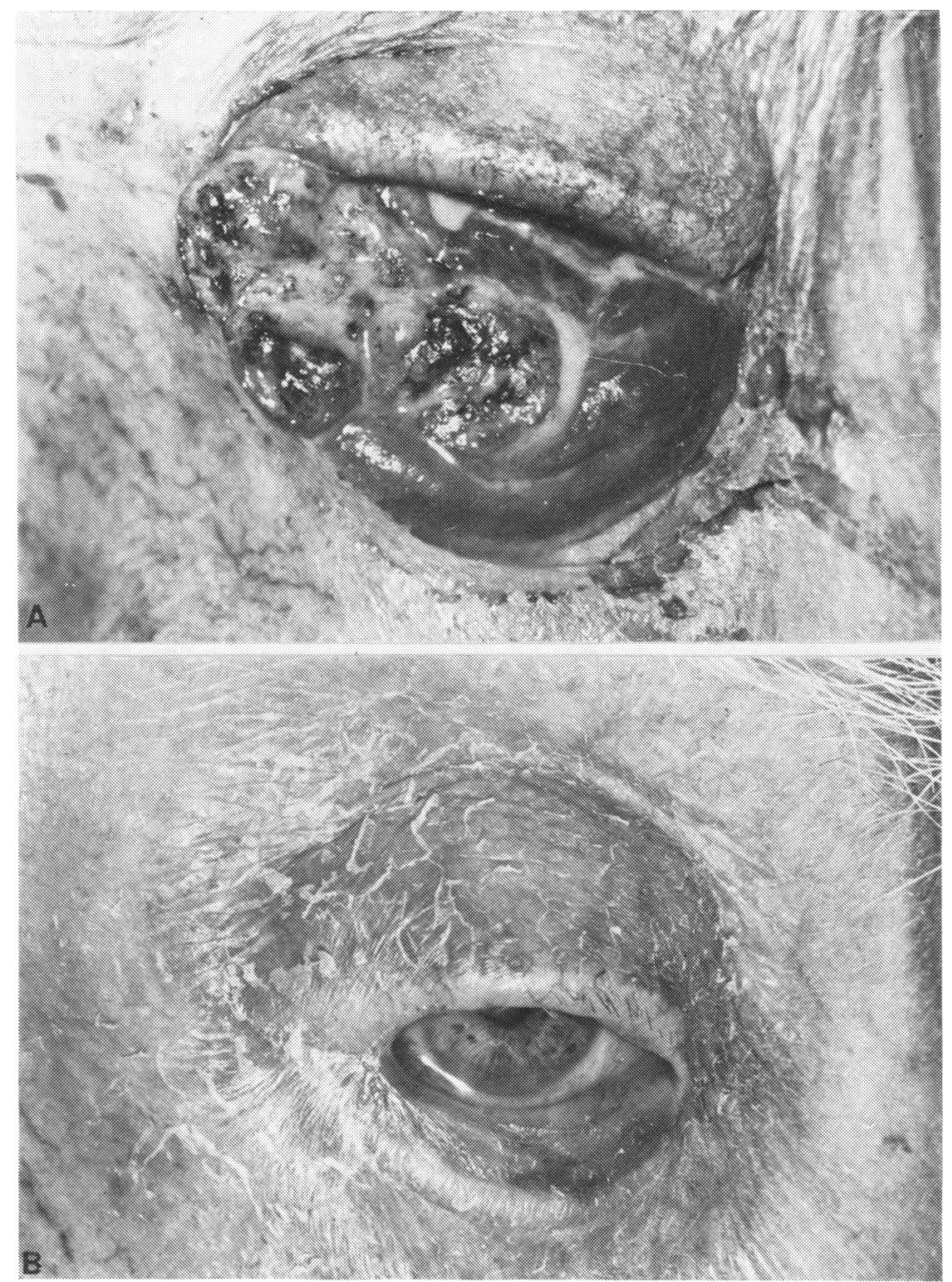

\section{Lid deformity ( 7 per cent)}

As many of the patients are elderly they have a natural tendency to laxness of the lower lid or even ectropion. If already existing this can be aggravated by radiotherapy. Alternatively, when a lid has been infiltrated by neoplasm for its whole thickness healing after radiation will be accompanied by fibrosis and when the tarsal plate is affected a contraction deformity will ensue. This type of deformity, usually ectropion, almost exclusively affects the lower lid. In the case of the upper lid, infiltration and destruction of the tarsal plate tend after successful radiation treatment to result in a coloboma rather than in a cicatricial deformity, Figs 8,9 , гоa, $b$.

Epiphora (10 per cent)

The possible occurrence of postradiation epiphora is frequently advanced as an argument against the use of radiotherapy. However, the obliteration or loss of the upper punctum occasions no problem: only when the lower punctum and canaliculus are stenosed or destroyed may epiphora occur. Mustardé and Jones (1970) in discussing the reconstructive surgery of the medial canthus point out that it is possible to remove the lacrimal passages completely without epiphora. After such an event epiphora will occur only in the presence of conditions giving rise to excessive tear formation. These are listed as being high wind, undue exposure of the conjunctiva, and in particular ectropion and also inflammatory conditions involving the lid margin, conjunctiva, cornea, or lacrimal sac.

These observations are supported by the events after radiation obliteration of the lacrimal passages. Only a small proportion of the patients in this 


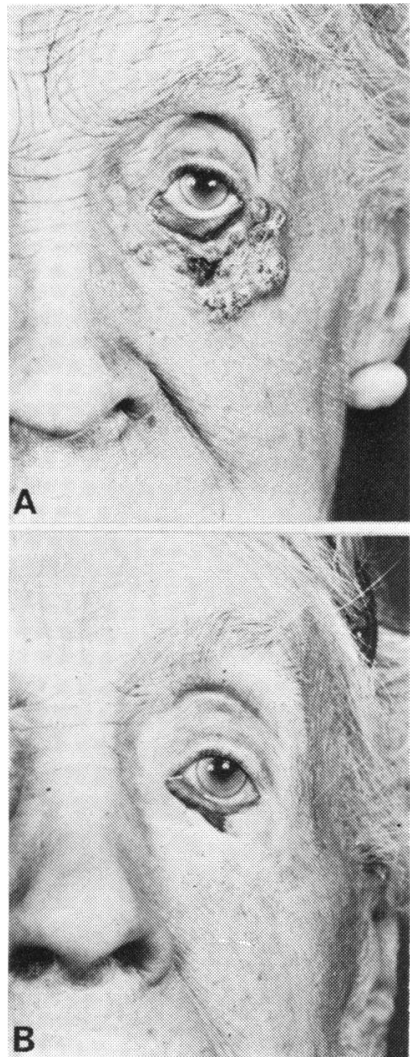

FIG. 9(a) Extensive tumour of left lower lid with invasion of fornix and destruction of tarsal plate

FIG. 9(b) After treatment

series (Io per cent) developed a troublesome epiphora and these were usually patients with a degree of lid deformity or some other local cause of reflex increase of tears.

This ability of the eye to accommodate itself to loss of the lacrimal passages means that attempts to maintain the patency of the punctum during or after radiotherapy, by irrigation, intermittent dilatation, the insertion of various kinds of dilator or operation are unnecessary. Efforts should rather be directed to ensuring that every cause of irritation that might give rise to a reflex increase in tear production should be sought and eliminated.

There is one factor that operates to the advantage of the patient with postradiation as opposed to postsurgical epiphora and that is that in many cases the epiphora appears to be self-limiting, tending to subside spontaneously within a year of treatment. The reason for this fortunate event is that radiation not only produces stenosis of the punctum but also destroys some of the secretory glands of the lid and conjunctiva so that there is a reduction in the total quantity of tears produced. At some point the impaired secretory mechanism and the damaged drainage system enter into compensatory equilibrium and the patient's eye no longer weeps.

\section{OTHER COMPLICATIONS, Table XI}

Keratinization of the conjunctival mucosa occurred in 5.6 per cent of cases. When this affected the lower lid problems could be avoided by regular removal of the keratin plaque and most patients can be taught to do this themselves. In the upper lid the keratin plaque is a potential menace to the cornea and a contact lens may be required to avoid corneal damage. Fortunately in recent years keratinization is less likely because of modifications in radiation technique whereby intense reactions are avoided.

Lid necrosis has occurred in patients with moderately atrophic skin changes or those with surgical scars. As a rule these necroses seem to occur in summer after exposure to an intense and unaccustomed degree of sunlight. The avoidance of bad scars, warning the patients against direct
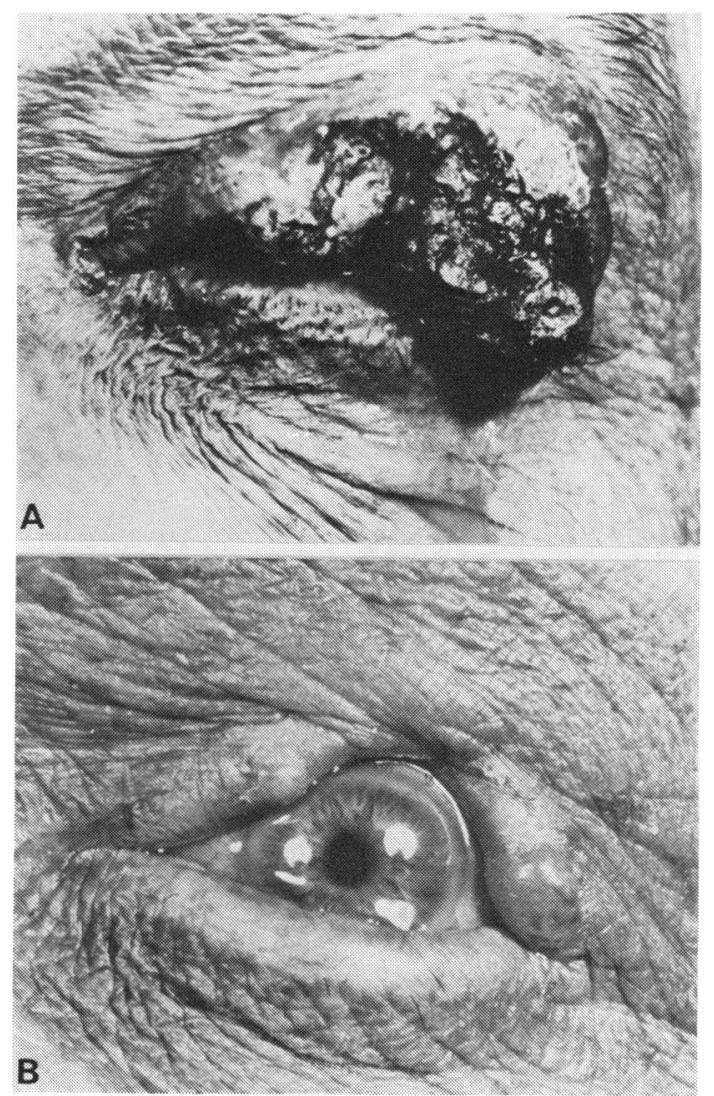

FIG. Io (a) Extensive tumour of upper lid with destruction of part of the tarsal plate; (b) after treatment showing lid coloboma 

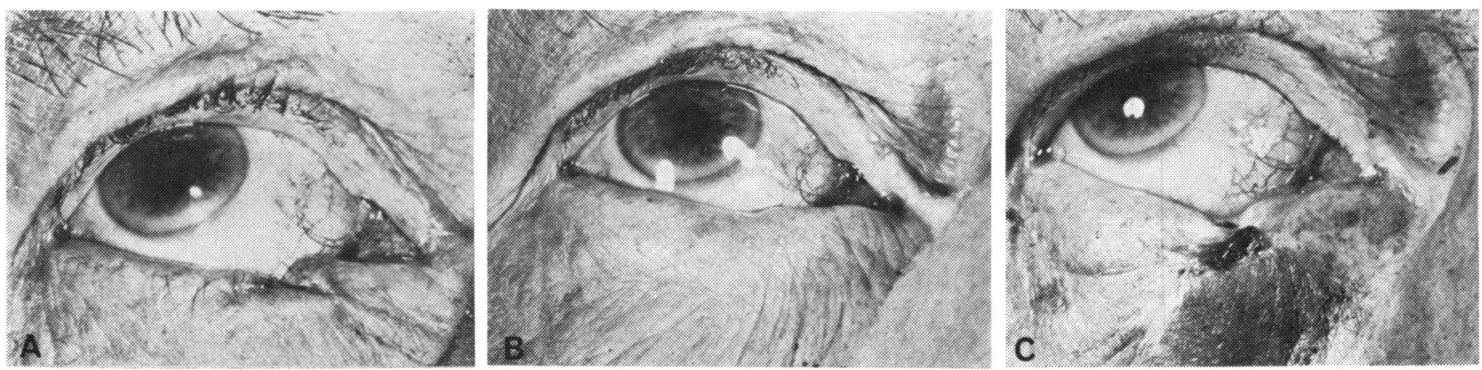

FIG. I I (a) Postoperative recurrence in scar before radiotherapy; (b) after radiotherapy; (c) skin necrosis after exposure to excessive sunlight

Table XI Incidence of complications

\begin{tabular}{|c|c|c|c|c|}
\hline \multirow{2}{*}{ Complication } & \multicolumn{2}{|c|}{ Basal cell } & \multicolumn{2}{|c|}{ Squamous cell } \\
\hline & No. & Percentage & No. & Percentage \\
\hline Lid necrosis & I 8 & $2 \cdot 9$ & 4 & \\
\hline Keratinization & 35 & $5 \cdot 6$ & 3 & \\
\hline Corneal ulceration & & & & \\
\hline or opacity & 10 & $\mathbf{r} \cdot 6$ & I & \\
\hline Corneal abrasion or & & & & \\
\hline keratitis & 13 & $2 \cdot I$ & $\mathbf{I}$ & \\
\hline Cataract & 5 & 0.8 & - & \\
\hline Eye removed & 3 & 0.5 & $\mathbf{I}$ & \\
\hline Any complication & 84 & $13 \cdot 3$ & 10 & 16 \\
\hline Total & 630 & & 59 & \\
\hline
\end{tabular}

exposure of the lids to intense sunlight, and the use of barrier creams all help. These sunlightinduced necroses heal readily with the application of a corticosteroid ointment once the solar-exposure factor is removed.

The corneal complications encountered were not due to direct irradiation of the cornea since in nearly all cases complete shielding of the cornea was achieved. Most of the corneal complications were due to exposure or irritation from secondary changes in the lid. The radiation cataracts occurred in patients treated by gamma radiation, usually in the form of a radon seed implant. In no case was it found necessary to deal with the cataract surgically. Of the three cases where the eye was lost, in two the eye was removed before the patient was referred for radiotherapy and in the third case a useless eye was removed because of involvement by uncontrolled disease.

\section{Prevention of complications}

GENERAL MEASURES

Patients undergoing the irradiation of a lid tumour inevitably develop a radiation reaction in the treated area. While this lid reaction ultimately subsides and is generally followed by few complications, the related bulbar conjunctiva and the cornea may, as already noted, be secondarily affected even though total protection of these tissues against irradiation has been provided. In addition many of the patients in the age groups concerned have incidental ocular problems requiring skilled care while the patient is undergoing radiotherapy. Because of this there is imperative need for ophthalmological control and care of the patient during treatment and the ophthalmologist has a vital part to play in any radiation unit dealing with these cases if unnecessary complications are to be avoided.

\section{CONTRAINDICATIONS TO RADIOTHERAPY}

The misuse of radiotherapy is understandable since it is a non-operative procedure readily available and easily applied. However, if complications are to be eliminated or reduced in frequency then the radiotherapist must be on his guard not to be enticed into treating a patient in circumstances where complications are inevitable or when treatment is accompanied by a high risk of postradiation damage. In these circumstances it is clearly better for the patient to submit to alternative, nonradiational methods. If no alternative is available or if available would entail removal of the eye then the radiation risks may be accepted as the lesser of two evils but this should be done only after a full discussion with both the patient and his doctors.

The following may be accepted as contraindications to radiotherapy:

\section{Recurrence after previous treatment}

Recurrent cases, whether the previous treatment be surgical or radiotherapeutic, should in principle be surgically treated if possible. If surgery is impractical then radiotherapy can be used, again with a good prospect of controlling the neoplasm but at an increased risk of a cosmetically unwelcome cicatrix and an added risk of radionecrosis. In this series of cases 3.8 per cent of the previously 
untreated patients were referred for surgery after radiotherapy either because of incomplete tumour regression or frank recurrence.

\section{Disease involving the mid-third of the upper lid}

Lesions in this situation are readily curable by radiotherapy but in the event of undesirable mucosal changes such as keratinization, secondary damage to the cornea is highly probable. This restriction on the use of radiotherapy in upper lid tumours applies only to small tumours centrally situated which would be amenable to simple excision and closure by direct approximation. If an upper lid tumour is sufficiently extensive to require a complicated reconstruction radiotherapy becomes a desirable alternative, since not only are the results excellent but there is always a good chance that keratinization may be avoided and even if it does occur and proves troublesome a contact lens provides a remedy. A sense of proportion has to be preserved in connexion with the risks of keratinization and no patient, particularly if elderly, should be persuaded to undergo a complicated and serious operation on the physiologically important upper lid unless some overriding reason other than the possibility of postradiation mucosal keratinization exists.

\section{The presence of a damaged cornea}

When the lid tumour is related to a cornea that is already abnormal or damaged in some way then as any subsequent postradiation lid changes may add further injury to the already damaged cornea surgery should be considered.

\section{Skin changes}

In outdoor workers or light-skinned patients, who already have solar skin changes, irradiation should be avoided especially if the patient lives in a tropical or subtropical climate.

\section{Bone invasion}

Radiotherapy is rarely successful in eradicating a tumour which has invaded bone. The advanced rodent ulcer accompanied by orbital bone invasion is best treated by a preliminary course of radiation followed by radical surgery.

\section{$A$ very small lesion remote from the canthus and lid margins}

Radiotherapy should be avoided in cases in which a biopsy excision would adequately remove the tumour.

\section{TECHNICAL MEASURES}

The technical steps the radiotherapist can take towards reducing the complications affecting the lids, conjunctiva, and the eye relate to the selection of apparatus and the dose and time factors of the treatment. Unwelcome cosmetic sequelae are more likely where radiation energies of $60 \mathrm{kV}$ or less are used and ocular complications are more likely when gamma-ray sources are implanted near the eye.

The intensity of the radiation reaction, the incidence of mucosal keratinization, and the cosmetic quality of the radiation scar can all be favourably influenced by attention to the fractionation of the dose and the length of the overall treatment time.

PROTECTIVE DEvices (Lederman and Jones, 1966)

The normal eye and the unaffected parts of the lids should be completely shielded. It is important to avoid trauma and sepsis when inserting the protective lead eye shields or spatulae. Even when the lids, eye, and orbital contents are involved by disease it is still possible to protect the cornea and the intraocular structures deep to it. To do this the radiation field has to be delineated by a light beam and an indirect method of shielding is employed wherein a lead absorber is placed in the beam of radiation so that the part of the eye that has to be protected is brought within the shadow produced by the interposed absorbing material.

This indirect method of shielding is of great value not only in the presence of orbital invasion but whenever the lids or fornices are deformed or destroyed and the direct insertion of a lead protective device proves impossible or potentially traumatic to the eye.

\section{ANCILLARY PROCEDURES}

The use of a haptic contact lens as a means of protecting the cornea against damage from secondary changes in the lids has proved of great value. The two chief indications are:

I. When tumours of the upper lid require radiation treatment and the risks of keratinization have to be guarded against.

2. When both upper and lower lids, particularly the lid margins, require treatment.

The risk of undesirable postradiation changes in the lids with secondary damage to the cornea is directly proportional to the length of lid margin treated. In these two instances the contact lens is made and fitted before treatment and worn throughout treatment and the period of reaction. If the reaction settles down without any serious lid sequelae the lens can be abandoned: otherwise its 
permanent use may be necessary. In order to prevent exposure keratitis with secondary keratinization or opacification of the cornea the patient with a serious postradiation lower lid deformity should be considered for plastic surgical correction of the deformity before signs of corneal exposure become apparent.

\section{Discussion}

It is believed that the results obtained in this series of cases, even accepting the incidence and the nature of the complications, would justify and support the continued advocacy of radiotherapy as the treatment of choice for malignant lid tumours.

It is difficult to determine the part that surgery should play in the treatment of these tumours since a survey of the surgical literature, particularly publications emanating from plastic surgical sources, are devoted almost exclusively to detailed accounts of surgical techniques. Any prolonged acquaintance with the treatment of malignant disease will demonstrate that cancer is no respecter of surgical expertise and for any given surgical procedure for lid cancer to be acceptable careful objective evaluation is necessary. If the rigid standards adopted by radiotherapists are to be followed it is essential that the description of any given operation be accompanied by its contraindications, complications, and the success rate achieved over at least a five-year period of observation. Nevertheless it must be accepted that in spite of the reliable results and obvious advantages of radiotherapy some cases are better treated by surgery particularly those contraindicating radiotherapy.

Any further scope for surgery should, assuming the patient is fit for operation, depend on the tumour size and situation and hence the simplicity or complexity of the operation needed.

If the size of tumour in this series (Tables VII $a$, $b$ ) is taken as representative it will be seen that of the basal cell carcinomas approximately one-third of the lid tumours and two-thirds of the inner canthus tumours would fall into category $T_{r}$ of the UICC system of classification. This means that allowing for a $5 \mathrm{~mm}$ margin of normal tissue these tumours were $2 \mathrm{~cm}$ or less in diameter and therefore presumably suitable for an operation not requiring plastic lid reconstruction (Mustardé and Jones, 1970). It should be noted that it is precisely these early cases that give the best results and fewest complications with radiation treatment. However, the remaining patients, namely the majority, would require excision and lid reconstruction with all that that entails by way of availability of the requisite surgical skills, the surgical risks for the elderly patient, to which must be added the economic disadvantages of surgical as opposed to radiotherapeutic treatment.

As neither surgery nor radiotherapy is a specific remedy for cancer, debate on their respective merits can prove endless. Effort can most profitably be expended on determining their relative spheres of usefulness in a complementary rather than a competitive sense. Until such time as more evidence concerning the true scope and value of surgery, particularly when associated with plastic lid reconstruction becomes available the patient's interests can best be safeguarded by ensuring collaboration between surgeon, radiotherapist, and dermatologist so that therapeutic decisions based on a partisan approach are avoided if possible.

I thank the many ophthalmologists who by sending their cases have made this study possible. I wish to single out in particular the members of the staff of the Moorfields Eye Hospital, City Road and High Holborn, and the Royal Eye Hospital. I am especially indebted to my colleagues at the Royal Marsden Hospital, Mr Shapland, Mr Wybar, and Mr Mallet, and to Mr Ruben of the High Holborn branch of Moorfields for dealing with the contact lens problems. I also thank Mr P. Payne, Director of the South Metropolitan Cancer Registry, for providing me with the statistical tables, and Miss Pegus and Mrs Potucek of the Medical Art and Photographic Departments of the Royal Marsden Hospital for the tables and illustrations. The editors of Ophthalmic Plastic Surgery Up-to-Date kindly gave permission to reproduce Figs 2 and 3 on page 4 of that book.

Dr B. Lewinsky, now at the Letterman Hospital, San Francisco, kindly helped with analysing the clinical material.

\section{References}

DUKE-ELDER, S. (1952) 'Textbook of Ophthalmology', vol. V. Kimpton, London

- (1974) 'System of Ophthalmology', vol. XIII, pt r. Kimpton, London

halman, K., and BRITTEN, M. (1960) Brit. F. Ophthal., 52, 43

HAYE, C., JAMMET, H., and DOllfus, M., (1965) 'L'Oeil et les Radiations', vol. II. Masson, Paris

LEDERMAN, M. (1964) $\boldsymbol{f}$. Laryng., 78, I 8I

, and JONES, c. (1966) 'Textbook of Radiotherapy', ed. G. Fletcher. Lea \& Febiger, Philadelphia

MUSTARDE, J., and JONES, L. T. (1970) 'Ophthalmic Plastic Surgery Up-to-Date'. Aesculapius, Alabama

UICC (1974) TNM Classification of Malignant Tumours. International Union Against Cancer, Geneva 